\title{
Role of sodium hyaluronate (Healonid) in triangular flap trabeculectomy
}

\author{
S O HUNG
}

From St Paul's Eye Hospital, Old Hall Street, Liverpool L3 9PF

SUMmARY The role of sodium hyaluronate (Healonid) in trabeculectomy to prevent a shallow or flat anterior chamber and hypotonia in the immediate postoperative period is reported. Twentynine eyes of 27 patients were included in a randomised controlled study. Thirteen eyes had trabeculectomy alone, and 16 eyes had trabeculectomy performed with Healonid injected into the anterior chamber. The results showed that shallowing of the anterior chamber and hypotonia occurred in both groups until day 21 postoperatively. There was no statistically significant difference between the two groups $(p>0 \cdot 05)$. Healonid has no significant value in maintaining anterior chamber depth and preventing hypotonia in the early postoperative period following trabeculectomy.

Since trabeculectomy was introduced by Cairns in $1968^{1}$ and later modified by Watson, ${ }^{2}$ it has become the most popular filtration procedure in the surgical management of glaucoma. One of the merits is a lower incidence of flat or shallow anterior chambers postoperatively as compared with other filtration surgery. ${ }^{3-10}$ The incidence of flat anterior chamber is from $2 \%$ to $4.5 \%$, while that of shallowing of the anterior chamber is $5 \%$ to $12 \% .^{3-10}$ The incidence of flat anterior chamber following iridencleisis is as high as $24 \%$ and even higher at $37 \%$ following Scheie's procedure." Despite the low incidence of flat anterior chambers following trabeculectomy it plays an important part in the development of cataract. $60 \%$ of cataracts that developed in the first six months following trabeculectomy had shallow or flat anterior chambers. ${ }^{10}$

Healonid is a high viscoelastic material with the properties of being non-antigenic and noninflammatory. ${ }^{12}$ It is capable of passing through a fine Rycroft cannula, so that it can easily be injected into the eye. It has been used in anterior segment surgical procedures, particularly in lens implantation ${ }^{13-14}$ and keratoplasty, as it can maintain a deep anterior chamber which allows surgical manipulation and minimises endothelial cell damage. ${ }^{15}$

There is an uncontrolled study which suggests that Healonid injected into the anterior chamber following trabeculectomy has a beneficial effect in reducing

Correspondence to Mr S O Hung, Warrington District General Hospital, Lovely Lanc, Warrington WA 5 1OG. the risk of flat anterior chamber. ${ }^{12} \mathrm{~A}$ randomised controlled study is reported here on the value of Healonid in trabeculectomy for preventing shallow or flat anterior chamber and hypotonia in the immediate postoperative period.

\section{Materials and methods}

Patients with open-angle glaucoma, or acute or intermittent closed-angle glaucoma with raised intraocular pressure above $21 \mathrm{mmHg}$ despite maximum medical treatment, were included in the study. Patients for combined cataract extraction and trabeculectomy, aphakic and rubeotic glaucoma, were excluded.

Having been selected for the study the patients were randomly assigned, so that they either had trabeculectomy alone or had trabeculectomy with Healonid injected into the anterior chamber.

\section{Table 1 Characteristics of patients}

\begin{tabular}{lcc}
\hline & No Healonid & Healonid \\
\hline Number of eyes & 13 & 16 \\
Mean age & $67 \cdot 5(52-86)$ & $67 \cdot 1(33-80)$ \\
Sex: male & 5 & 10 \\
$\quad$ female & 8 & 6 \\
Mean preop. IOP & 30.4 & 28.6 \\
Mean preop. ACD & 2.4 & $2 \cdot 4$ \\
Mean outflow facility & 0.06 & 0.06 \\
\hline
\end{tabular}


All patients received full ophthalmological examinations preoperatively. Snellen's visual acuity was recorded, intraocular pressure was measured with a Goldmann applanation tonometer, the depth of the anterior chamber was measured with a Jaeger depth micrometer, gonioscopy was done, outflow facility was recorded by tonography, and the density of cataract, if present, was recorded diagrammatically.

Trabeculectomies were performed under general or local anaesthesia. The surgical technique used is based on that described by Watson ${ }^{2}$ with a modification involving the use of a limbal based triangular half thickness lamellar scleral flap measuring $5 \times 5 \times 5$ mm. ${ }^{16}$ A rectangular $4 \times 2 \mathrm{~mm}$ sclerotrabecular lamella is then excised, peripheral iridectomy performed, and the apex of the triangular scleral flap stitched back to the original place with a single 8.0 virgin silk. A corneal paracentesis at 10 or 2 o'clock is made with a Graefe knife at the beginning of the operation so that Healonid can be injected into the anterior chamber through this at the end of the operation, resulting in deepening of the anterior chamber until Healonid is extruded through the trabeculectomy fistula into the subconjunctival space.

All patients were treated with Predsol $\mathrm{N}$ eye drops (prednisolone sodium phosphate $0.5 \%$, neomycin sulphate $0.5 \%$, thiomersal $0.005 \%$ ) four times a day and atropine $1 \%$ eye drops twice daily for three weeks postoperatively. They were examined on days $1,2,3,7,21$, and 42 postoperatively, and a record of the intraocular pressure, anterior chamber depth, severity of anterior uveitis, hyphaema, choroidal detachment, and cataract was made.

\section{Results}

Twenty-nine eyes of 27 patients were included in the study. Thirteen eyes had trabeculectomy alone of which 12 had open-angle glaucoma, and one acute closed-angle glaucoma. Sixteen eyes had trabeculectomy with Healonid injected into the anterior chamber of which 11 eyes had open-angle glaucoma, two acute closed-angle glaucoma, and three intermittent closed-angle glaucoma. The two groups were comparable for age, sex, preoperative mean anterior chamber depth, intraocular pressure, and outflow



Fig. 1 Frequency distribution of the amount of shallowing of the anterior chamber. 
Table 2 Mean anterior chamber depth $(\mathrm{mm})$

\begin{tabular}{llllllll}
\hline & Preop. & Day 1 & Day 2 & Day 3 & Day 7 & Day 21 & Day 42 \\
\hline No Healonid & 2.4 & 1.7 & 1.9 & 1.9 & 1.9 & 2.4 & 2.4 \\
Healonid & 2.4 & 1.5 & 1.3 & 1.3 & 1.5 & 2.3 & 2.3 \\
\hline
\end{tabular}

facility (Table 1). Two eyes in the Healonid treated group had flat anterior chamber, and there was no flat anterior chambers in the group without Healonid. The frequency distribution of the amount of shallowing of the anterior chamber is shown in Fig. 1. The mean anterior chamber depths are shown in Table 2. There is no statistically significant difference in the two groups as analysed by Student's $t$ test $(\mathrm{p}>0.05)$.

The frequency distribution of postoperative intraocular pressure is shown in Fig. 2. The mean intraocular pressures are shown in Table 3. There is no statistically significant difference between the two groups as analysed by Student's $t$ test $(\mathrm{p}>0.05)$. The incidence of hyphaema and choroidal detachment is shown in Table 4. All hyphaemas resolved spon- taneously by day seven, and choroidal detachment settled spontaneously by day 21 .

\section{Discussion}

Two eyes in the Healonid treated group had flat anterior chambers. This occurred in one eye on day seven and was associated with a choroidal detachment. The anterior chamber reformed spontaneously the following day. In the second eye the flat anterior chamber occurred on day four and had to be reformed on day seven. These two eyes subsequently developed anterior subcapsular cataracts.

It is evident from the frequency distribution of the amount of shallowing of the anterior chamber in Fig.

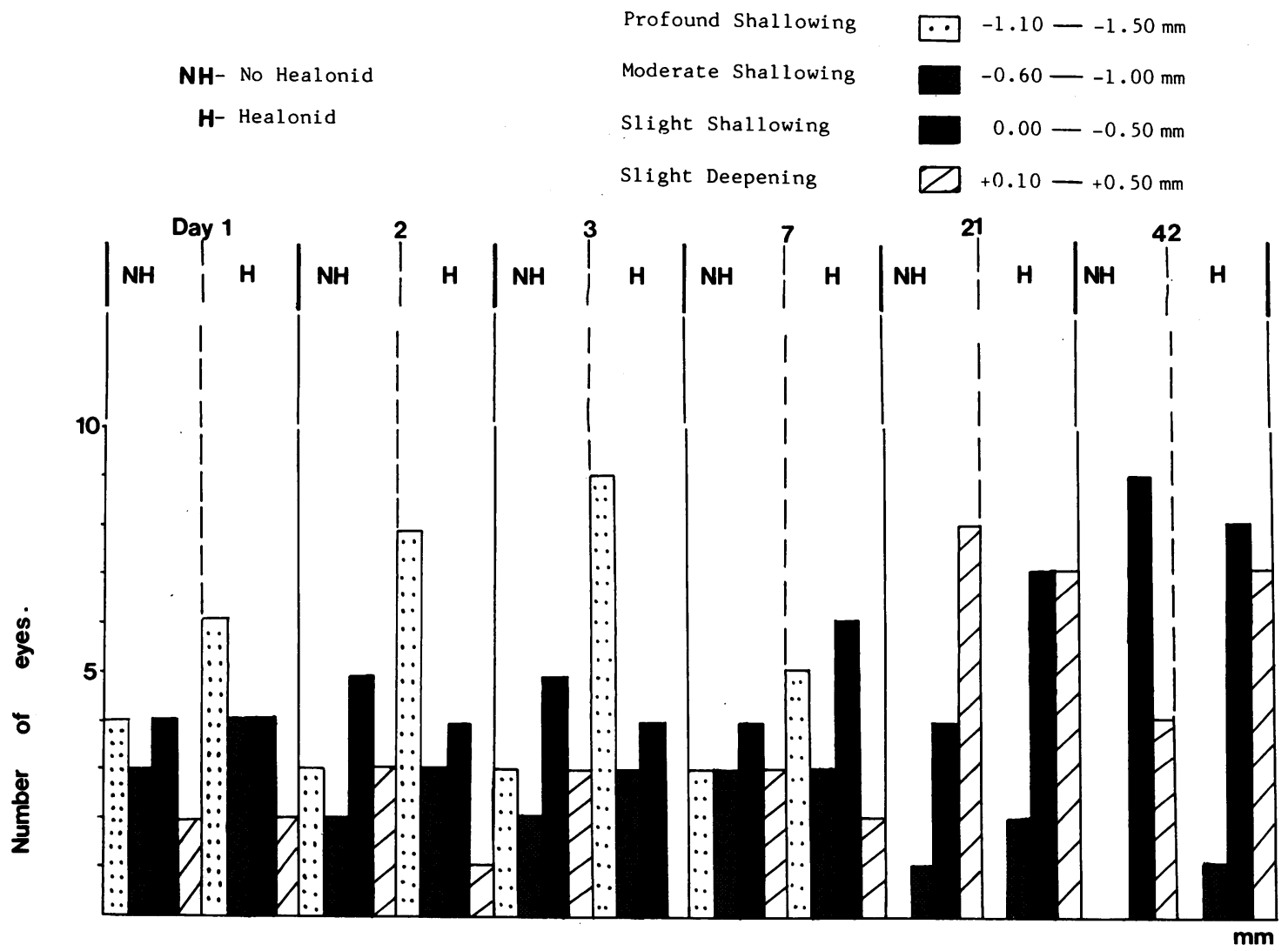

Fig. 2 Frequency distribution of postoperative intraocular pressure. 
Table 3 Mean intraocular pressure $(\mathrm{mmHg})$

\begin{tabular}{|c|c|c|c|c|c|c|c|}
\hline & Preop. & Day 1 & Day 2 & Day 3 & Day 7 & Day 21 & Day 42 \\
\hline No Healonid & $30 \cdot 4$ & $5 \cdot 6$ & $7 \cdot 8$ & $5 \cdot 7$ & $8 \cdot 0$ & $10 \cdot 5$ & $10 \cdot 6$ \\
\hline Healonid & $28 \cdot 6$ & $5 \cdot 8$ & $7 \cdot 3$ & $6 \cdot 1$ & $5 \cdot 6$ & $10 \cdot 3$ & $12 \cdot 8$ \\
\hline
\end{tabular}

Table 4 Other complications

\begin{tabular}{lll}
\hline & No Healonid & Healonid \\
\hline Hyphaema & $9(69 \cdot 2 \%)$ & $10(62 \cdot 5 \%)$ \\
Choroidal detachment & $3(23 \%)$ & $7(44 \%)$ \\
\hline
\end{tabular}

1 that more than $50 \%$ of the eyes in both groups had either profound or moderate shallowing of the anterior chamber until day $7.92 \%$ of the eyes in the no Healonid group and $87 \%$ of the Healonid treated group had either slight shallowing or slight deepening of the anterior chamber on day 21 . The mean anterior chamber depth also returned to preoperative level in both groups on day 21 .

From the frequency distribution of postoperative intraocular pressure in Fig. 2 it is clear that there was a higher incidence of hypotonia below $10 \mathrm{mmHg}$ in both groups up to day seven. The mean intraocular pressure above $10 \mathrm{mmHg}$ was atiained on day 21 in both groups.

The incidence of choroidal detachment in both groups was higher than in other studies, ${ }^{310}$ because fundal examination was carried out in search of this complication every time the patient was seen. The eyes with choroidal detachment are associated with profound or moderate shallowing of the anterior chamber. All choroidal detachment resolved spontaneously by day 21 at the same time as the mean anterior chamber depth returned to preoperative level. The results indicate that sodium hyaluronate (Healonid) has no significant value in maintaining

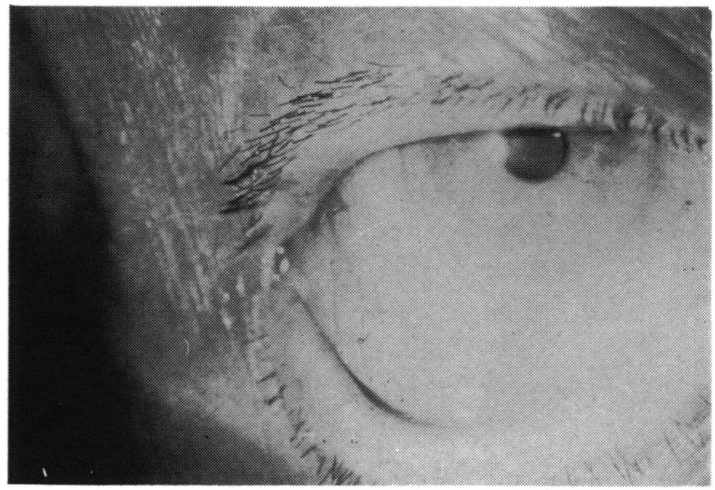

Fig. 3 Healonid accumulated in the lower fornix. anterior chamber depth and preventing hypotonia in the immediate postoperative period.

The use of Healonid for lens implantation is safe and free from complication except for an ocular hypertensive effect. ${ }^{17}$ This is because of the presence of a watertight wound following lens implantation. However, in trabeculectomy Healonid will be extruded through the trabeculectomy fistula if there is any rise in intraocular pressure. Indeed, Healonid is seen to accumulate in the subconjunctival space in the lower fornix (Fig. 3) on the first postoperative day in cases where there is profound shallowing of the anterior chamber.

The presence of Healonid in the anterior chamber gives the appearance of plastic anterior uveitis which disappears by the third postoperative day. Although it is not known exactly how long Healonid stays in the anterior chamber, this clinical observation indicates that Healonid leaves the anterior chamber by the third postoperative day after being diluted with aqueous as Healonid is a hydrophilic substance. ${ }^{12}$ Therefore, the extrusion of the Healonid through trabeculectomy fistula and the dilution of Healonid with aqueous may be the contributory factors for the failure of Healonid to act as an internal tamponade in the anterior chamber despite its initial high viscoelasticity.

I thank Mr M Burns, Mr T D H Gray, and Mr A Patterson for allowing $\mathrm{me}$ to study their patients. In particular I thank $\mathrm{Mr}$ $\mathrm{R}$ Mapstone for his advice and encouragement and also $\mathrm{Mr} \mathrm{A}$ Akingbehin for his advicc. I am grateful to Mr Moody for his photographic assistance.

\section{References}

1 Cairns JE. Trabeculectomy. Am J Ophthalmol 1968; 66: 673-9.

2 Watson PG. Trabeculectomy, a modified ab externo technique. Ann Ophthalmol 1970; 2: 199-205.

3 Ridgway AEA, Rubinstein K, Smith VH. Trabeculectomy-a study of 86 cases. Br J Ophthalmol 1972; 56: 511-6.

4 Thyer HW, Wilson P. Trabeculectomy. Br J Ophthalmol 1972; 65: $37-40$.

5 Watson PG, Barnett F. Effectiveness of trabeculectomy in glaucoma. Am J Ophthalmol 1975; 79: 831-45.

6 McPherson SD Jr, Cline JW, McCurdy D. Recent advances in glaucoma surgery. Trabeculotomy and trabeculectomy. Ann Ophthalmol 1977; 9: 91-6.

7 D'Ermo F, Bonomi L, Duro D. A critical analysis of the longterm results of trabeculectomy. Am J Ophthalmol 1979; 88: 829-35. 
8 Murray SB, Jay JL. Trabeculectomy, its role in the management of glaucoma. Trans Ophthalmol Soc UK 1979; 99: 492-4.

9 Zaidi AA. Trabeculectomy, a review and 4-year follow up. $\mathrm{Br} \mathrm{J}$ Ophthalmol 1980; 64: 436-9.

10 Mills KB. Trabeculectomy: a retrospective long-term follow up of 444 cases. Br J Ophthalmol 1981; 65: 790-5.

11 Scheie HG. Filtration operations for glaucoma: a comparative study. Am J Ophthalmol 1962; 53: 571-90.

12 Balazs EA, Freeman MI, Klöti R, et al. Hyaluronic acid and replacement of vitreous and aqueous humour. Mod Probl Ophthalmol 1972; 10: 3-21.
13 Miller D, Stegmann R. Use of sodium hyaluronate in human I.O.L. implantation. Ann Ophthalmol 1981; 13: 811-5.

14 Choyce DP. Healon in anterior chamber lens implantation. Am Intraocular Implant Soc J 1981; 7: 138-9.

15 Pape LG, Balazs EA. The use of Na-hyaluronate in human anterior segment surgery. Ophthalmology 1980; 87: 699-705.

16 Singh D, Singh $M$. Pretrabecular filtration for secondary glaucoma. Trans Ophthalmol Soc UK 1978; 98: 89-92.

17 Percival SPB. Complications from use of sodium hyaluronate (Healonid) in anterior segment surgery. Br J Ophthalmol 1982; 66: 714-6. 